\title{
Estabilidade de emulsões: um estudo de caso envolvendo emulsionantes aniônico, catiônico e não-iônico
}

\section{Emulsion stability: a case study involving anionic, cationic and nonionic emulsifiers}

\author{
Angélica Franzol ${ }^{1}$ e Mirabel Cerqueira Rezende ${ }^{1,2 *}$ \\ 'Departamento de Materiais e Processos, Instituto Tecnológico de Aeronáutica - ITA, \\ São José dos Campos, SP, Brasil \\ ${ }^{2}$ Instituto de Ciência e Tecnologia - ICT, Universidade Federal de São Paulo - UNIFESP, \\ São José dos Campos, SP, Brasil \\ *mirabel@pq.cnpq.br
}

\begin{abstract}
Resumo
Este artigo explora conceitos teóricos que se apresentam como estratégica na formulação de emulsões. Emulsões são sistemas termodinamicamente instáveis e o objetivo de todo formulador é estabelecer critérios técnicos na escolha de componentes para atingir a estabilidade cinética. Estudos de décadas trazem lucidez para que melhores resultados sejam atingidos, na estabilização de sistemas emulsionados. Nesse sentido, este artigo faz uma exploração prática comparando três emulsionantes (aniônico, catiônico e não-iônico) nas concentrações de 1, 3 e 5\% em massa, para um melhor entendimento da aplicação da química na escolha do tipo de emulsionante e sua concentração na proposição de um sistema emulsionado. A comparação realizada é baseada em medidas de tamanhos de gotículas de fórmulas preparadas. Os resultados apresentados ilustram a contribuição das características químicas das moléculas dos emulsionantes na estabilidade do sistema e também o quanto é importante o conhecimento prévio das teorias de emulsões (apresentadas neste artigo) para atingir o sucesso na obtenção de sistemas cineticamente estáveis.
\end{abstract}

Palavras-chave: emulsão, estabilidade, tamanho de gotículas.

\begin{abstract}
This article uses theoretical strategies for the design of emulsions formulation. Emulsions are considered as thermodynamically unstable systems and all formulators aim to establish the right technical criteria for choosing the right components and reach kinetic stability. Since some decades ago, theories were developed and this knowledge has contributed for better results involving the stabilization of emulsion systems. For a better understanding of the chemistry supporting the emulsifier selection and its concentration behind a stable system proposition, this article presents a practical application involving three different emulsifiers (anionic, cationic and nonionic) at 1, 3 and 5\% in weight. The comparison is based on particle size analyses of droplets of the prepared formulas. The results show the contribution of the chemical characteristics of the emulsifiers on the system stabilization and the importance of prior knowledge of the emulsions theories (presented in this article) to succeed in obtaining kinetically stable systems.
\end{abstract}

Keywords: emulsion, stability, emulsion droplet size analysis.

\section{Introdução}

Emulsões são definidas como um sistema polifásico, no qual se encontra uma fase fragmentada (fase dispersa) dentro de uma outra (fase contínua) ${ }^{[1]}$. O comportamento de uma emulsão depende fortemente do tamanho dos fragmentos da fase dispersa, sejam eles bolhas ou gotículas. Em uma emulsão, uma fase líquida (descontínua ou interna) é estabilizada em outra fase líquida (contínua ou externa) pela ação de um emulsionante. A noção de estabilidade em emulsões é dada por meio do tempo necessário para o início visual de separação de fases e pode levar de alguns minutos a alguns anos. Emulsões muito estáveis demoram

muito tempo para separar fases. Esse tempo esperado para o início de separação é relativo à aplicação da emulsão ${ }^{[1-4]}$. Existem diversas aplicações para emulsões, podendo-se citar no ramo alimentício (maionese, manteiga, sorvetes, leite), revestimentos (tintas), agroquímicos, petróleo e cosméticos ${ }^{[5]}$.

Para uma emulsão atingir estabilidade cinética, uma combinação adequada de ingredientes deve ser alcançada. Portanto, utilizando conhecimentos de química para estabilizar o sistema e variando questões de processo de fabricação, a estabilidade cinética pode ser atingida. 
Este artigo tem por objetivo apresentar de maneira clara e didática uma revisão sobre conceitos básicos que envolvem emulsões e ilustrar o efeito da utilização de três diferentes classes de emulsionantes - aniônico, catiônico e não-iônico - no tamanho e na distribuição de gotículas emulsionadas em uma formulação base de cosmético. Nesse sentido, a parte experimental deste trabalho dedica especial atenção às emulsões que possuem água (A) como fase externa e óleo $(\mathrm{O})$ como fase interna, portanto emulsões $\mathrm{O} / \mathrm{A}$. No entanto, sabe-se que esses mesmos conceitos, em sua maioria, podem ser aplicados a qualquer tipo de emulsão. Os aspectos químicos dos emulsionantes aniônico, catiônico e não-iônico são explorados em maior profundidade e os aspectos físicos em menor profundidade.

\section{Formação de Micelas}

Quando surge a necessidade de se entender o mecanismo de formação de micelas, em um sistema composto por água e emulsionante, a literatura apresenta várias informações relativas ao formato da micela em função do aumento da concentração do emulsionante ${ }^{[1-6]}$. No entanto, quando são necessários maiores esclarecimentos técnicos envolvendo uma emulsão e a menor unidade organizada - a gotícula ou o glóbulo emulsionado, já não há tanta informação disponível na literatura ${ }^{[1-6]}$. Isso está relacionado à complexidade do sistema, ainda pouco explorada, e às infinitas combinações de ingredientes, onde cada um imprime uma característica química ao sistema, mesmo quando em baixas concentrações. Nesse caso, elucidações são atingidas por meio de experiência técnica adquirida na realização de experimentos e do conhecimento de teorias utilizadas no entendimento de sistemas poliméricos, por exemplo.

A gotícula ou o glóbulo emulsionado é uma estrutura globular formada por um agregado de moléculas anfipáticas, ou seja, compostos que possuem características polares e apolares simultaneamente, dispersa em um líquido, constituindo uma das fases de um coloide ${ }^{[2]}$. Essas estruturas são geralmente globulares, contudo, podem ser também elipsoides, cilíndricas e em camadas. Essas estruturas variam entre 0,1 e 0,001 $\mu \mathrm{m}$. As gotículas se mantêm em constante e errático movimento, chamado browniano, graças à repulsão entre elas, causada pela presença de cargas elétricas.

A Figura 1 ilustra, esquematicamente, como os glóbulos emulsionados se organizam em um meio disperso. Ao invés de todos os ingredientes da emulsão, somente a molécula de um emulsionante etoxilado está descrita para facilitar a visualização do esquema. A ilustração permite concluir que os elementos polares da formulação possuem maior afinidade por água, portanto fica na fase externa. Já os ingredientes apolares apresentam maior afinidade por óleo, portanto ficam dispersos na parte interna de cada gotícula. A ponta apolar da cadeia fica escondida (da água), devido ao processo dinâmico de movimentação (movimento browniano), mas não ficam esticadas por uma implicação entrópica. Esticadas estariam no estado sólido e não seria possível solubilizar algo ali ${ }^{[3]}$.

A coalescência de uma emulsão ocorre com a união de duas ou mais parcelas de uma fase em prol da formação de uma única. É comum encontrar o termo 'única' ao se referir à formação de uma gotícula de água líquida única, por reunião de duas ou mais gotículas que entram em colisão. Também é largamente utilizado quando ocorre a junção de duas ou mais bolhas de ar dispersas em um líquido, de modo que elas se fundem em menos bolhas, mas de maiores dimensões ${ }^{[1]}$.

Esse processo pode ser acelerado submetendo amostras a temperaturas mais elevadas $\left(40^{\circ} \mathrm{C}\right.$, por exemplo). A elevação da temperatura aumenta a quantidade de choques moleculares e acelera a separação (o aumento da energia cinética impacta no equilíbrio termodinâmico). Para reduzir a probabilidade de coalescência, a cinética pode ser desacelerada com o aumento da viscosidade, tamanho uniforme das gotículas e solubilidade ${ }^{[4,7]}$. Detalhes são discutidos nos próximos itens.

Quando a colisão é impedida (congelamento), é esperado que o sistema conserve a característica original ao voltar à temperatura ambiente ${ }^{[8-13]}$. A Figura 2 mostra esquematicamente os tipos de separação em emulsões.

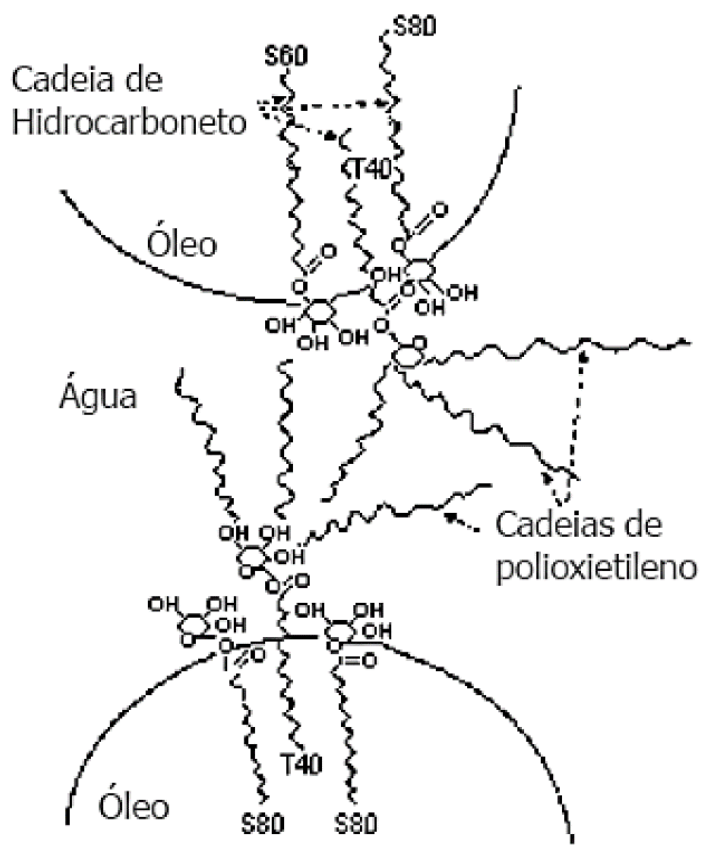

Figura 1. Esquema ilustrativo da organização das gotículas de uma emulsão ${ }^{[1]}$

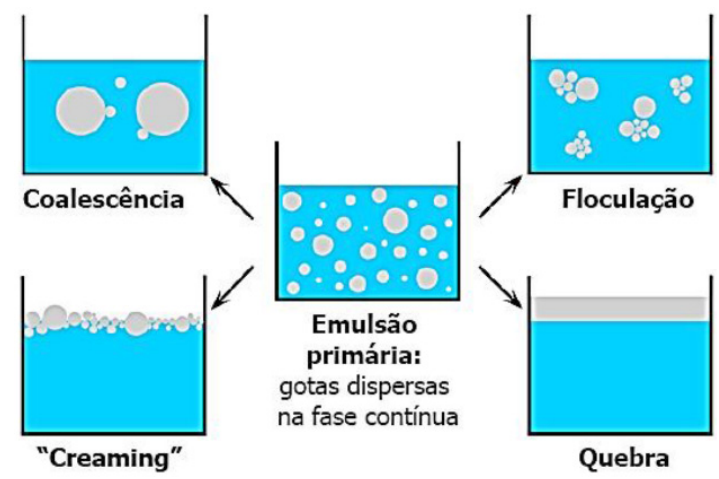

Figura 2. Tipos de separação em emulsões ${ }^{[8,9]}$. 
A sedimentação ou creaming resulta de uma diferença de densidade entre as duas fases e consiste na migração de uma das substâncias para o topo da emulsão, não sendo necessariamente acompanhada de floculação das gotas. É reversível, portanto após agitação, a emulsão retorna à sua condição original ${ }^{[1,7-9]}$.

Stokes demonstrou, em 1851, a possibilidade de se determinar a velocidade de sedimentação de uma emulsão propondo a Equação 1. A Lei de Stockes é válida para o movimento de gotículas esféricas pequenas, movendo-se a velocidades baixas, a qual foi comprovada experimentalmente aplicando-se o conceito a vários fluídos e condições ${ }^{[2]}$.

$$
V_{s}=2 / 9 r^{2} g\left(\rho_{p}-\rho_{f}\right) / \eta
$$

onde: $V_{s}$ é a velocidade de sedimentação; $g$ é a aceleração da gravidade; $\rho_{p}$ é a densidade da gotícula; $\rho_{f}$ é a densidade do fluído, $r$ é o raio da gotícula e $\eta$ é a viscosidade da fase contínua da emulsão. O número gerado é relativo e sistemas com estabilidade cinética conhecida devem ser adotados como padrão de comparação.

As colisões entre gotas podem resultar em floculação, que pode levar à coalescência em glóbulos maiores. Eventualmente, a fase dispersa pode se tornar a fase contínua, separada da dispersão média por uma única interface. Neste caso, tem-se a emulsão totalmente separada (quebra) ${ }^{[1]}$.

Observado pela primeira vez por Ostwald, em 1896, o fenômeno de amadurecimento de Ostwald consiste no crescimento do raio da gotícula e na diminuição do número total das gotículas dispersas (Figura 3). Esse efeito evidencia a condição de um sistema termodinamicamente instável, ou seja, um processo que não é espontâneo. É este efeito que leva à separação da emulsão com o passar do tempo ${ }^{[14-17]}$.

A seguir são descritas as principais teorias relacionadas à formação de micelas e cada tópico contém explicações e propostas de ordem prática.

\subsection{Teorias Relacionadas à Formação de Micelas}

\subsubsection{Efeito Gibbs-Marangoni}

A coalescência envolve a redução do filme entre as gotas até uma espessura crítica, por meio da drenagem da fase contínua entre elas, seguida da remoção de emulsionantes. Assim, são gerados gradientes de tensão interfacial à medida que as espécies são removidas da interface. A tendência dos gradientes de tensão, que foram criados pelo estresse na interface, seja por colisão das gotas, por cisalhamento ou alongamento pela aplicação de um campo elétrico, é que se oponham a este efeito e tentem restaurar a condição inicial uniforme da interface. O efeito de Gibbs-Marangoni descreve a difusão dos compostos na película do filme interfacial no sentido oposto à drenagem do filme. A Figura 4 ilustra este efeito para uma emulsão água em óleo - $\mathrm{A} / \mathrm{O}^{[2,18-20]}$. O mecanismo é o mesmo para aplicação conceitual em um sistema emulsionado óleo em água - O/A, como o estudado neste artigo.

Os glóbulos emulsionados não são estáticos. Um glóbulo emulsionado se desfaz e se forma várias vezes, principalmente, devido ao movimento browniano. Por isso, o filme interfacial deve se apresentar mecanicamente estável e com comportamento viscoelástico ${ }^{[2]}$. A Figura 5 ilustra a dinâmica encontrada na fase dispersa de uma emulsão água em óleo - $\mathrm{A} / \mathrm{O}^{[2]}$. A dinâmica ocorre da mesma maneira, quando a ideia é aplicar este conceito para uma emulsão óleo em água - O/A, como as estudadas na parte experimental deste artigo.

A tensão interfacial deve ser levada em conta na escolha dos emulsionantes e ingredientes para que haja adsorção garantida no filme interfacial[ ${ }^{[21]}$. Os emulsionantes se concentram na superfície e menor energia é gasta para fazer o movimento de interface. Quanto maior a cadeia apolar do emulsionante, maior a capacidade de reduzir a tensão superficial de emulsões $\mathrm{O} / \mathrm{A}^{[24]}$.
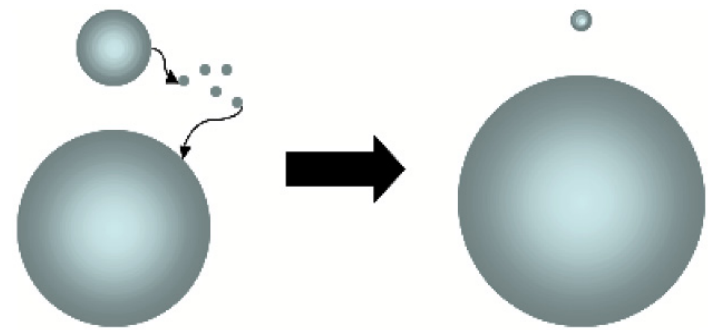

Figura 3. Amadurecimento de Ostwald ${ }^{[1]}$.

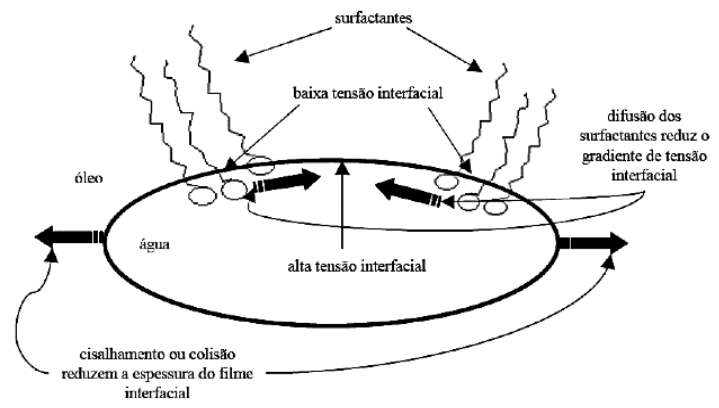

Figura 4. Efeito de Gibbs-Marangoni ${ }^{[2]}$. Fatores que alteram a tensão interfacial: água, óleo e emulsionantes, diminuem a tensão interfacial ${ }^{[21]}$. Já o cisalhamento ou colisão reduzem a espessura do filme por aumentar a tensão interfacial ${ }^{[22-24]}$.

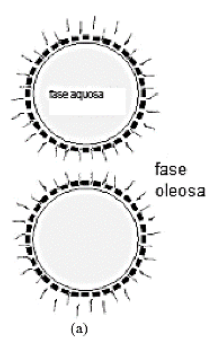

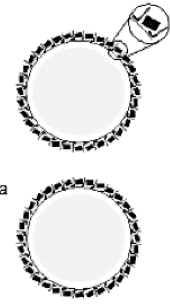

(b)

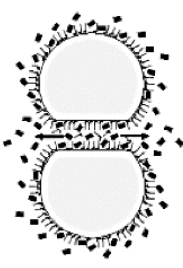

(c)

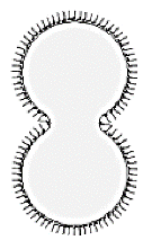

Figura 5. Efeito Gibbs-Marangoni em uma emulsão O/A (a) gotícula cercada por emulsionante; (b) interação entre emulsionante e fase interna; (c) dinâmica de "desemulsificação" devido ao movimento browniano; (d) coalescência devido ao filme na interface não oferecer suficiente estabilidade mecânica e viscoelasticidade ${ }^{[2]}$. 


\subsubsection{Forças de interações intermoleculares}

Na escolha do emulsionante mais adequado deve-se contar com forças de van der Waals, eletrostática e hidrofóbica ${ }^{[2]}$. As forças de van der Waals (Figura 6) são definidas pelo momento dipolo ( $\mathrm{p}$ ) e quanto maior for $\mathrm{p}$, maior a distância $\mathrm{L}$ ou maior a diferença entre as cargas $(\mathrm{q})^{[2]}$.

A contribuição das forças de interação na termodinâmica de micelinização está relacionada à parcela de entalpia $(\Delta \mathrm{H})$, enquanto a parcela de entropia $(\Delta \mathrm{S})$ está associada à possibilidade de arranjos das moléculas na equação de Gibbs (Equação 2) ${ }^{[3,13]}$.

$$
\Delta \mathrm{G}=\Delta \mathrm{H}-\mathrm{T} \Delta \mathrm{S}
$$

O equilíbrio na distribuição espacial somente ocorre quando uma força, do tipo cisalhante, é aplicada ao sistema, pois a organização nunca ocorreria de forma espontânea. A estabilização espontânea do sistema seria uma violação à segunda Lei de Newton, que prevê que a entropia (aleatoriedade) somente pode ser alterada em uma direção. Os ingredientes que apresentam polaridades diferentes, portanto afinidades distintas, não se misturam, porque o processo é dominado pela parcela da entropia extremamente positiva e sistemas espontâneos ocorrem na natureza quando $\Delta \mathrm{G}$ é negativo ${ }^{[3,13]}$.

A aplicação de energia em uma emulsão para garantir a formação da menor unidade organizada do sistema (glóbulo emulsionado), significa a aplicação direta do conceito da segunda Lei de Newton, de modo a favorecer a formação de arranjos e produzir uma mudança negativa na entropia do sistema, isto é, fazer o $\Delta \mathrm{S}$ ser alterado na direção oposta àquela que ocorre naturalmente ${ }^{[3,13]}$.

A interação eletrostática também exerce grande influência na estabilidade de emulsões, já que a interação eletrostática está presente, mesmo quando a distância entre átomos é aumentada em 60 vezes ${ }^{[2]}$.

A presença de carga elétrica na superfície de uma gotícula, em contato com a água, provoca o aumento da concentração de contraíons junto à superfície. Assim, forma-se uma dupla camada elétrica (camada de Stern) na interface da gotícula com o líquido (Figura 7).

Em um campo elétrico, como em microeletroforese, cada gotícula e os íons mais fortemente ligados à mesma se movem como uma unidade, e o potencial no plano de cisalhamento entre essa unidade e o meio circundante é chamado potencial zeta ${ }^{[7]}$.

O potencial zeta é um indicador útil de balanceamento de cargas e pode ser usado para prever e controlar a estabilidade de suspensões ou emulsões coloidais. Quanto maior o potencial zeta, mais provável que a suspensão seja estável, pois as gotículas carregadas se repelem umas às outras e essa força supera a tendência natural de agregação ${ }^{[2,3,7]}$.

Ainda pode-se contar com o fenômeno da hidrofobicidade para garantir a estabilidade da emulsão, escolhendo o emulsionante adequado. Empiricamente, Brancroft (1913) determinou que o emulsionante deve ser mais solúvel na fase contínua e Griffin (1949) estabeleceu o balanço hidrofílico-lipofílico (HLB), na tentativa de quantificar e localizar o emulsionante na interface, para estabelecer

\section{$\vec{p}=q \vec{L}$}

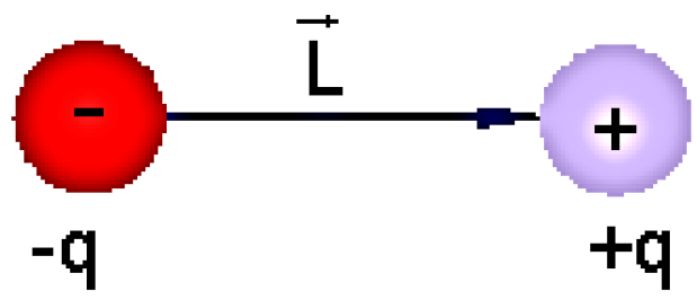

Figura 6. Esquema que ilustra as forças de van der Waals ${ }^{[8]}$.

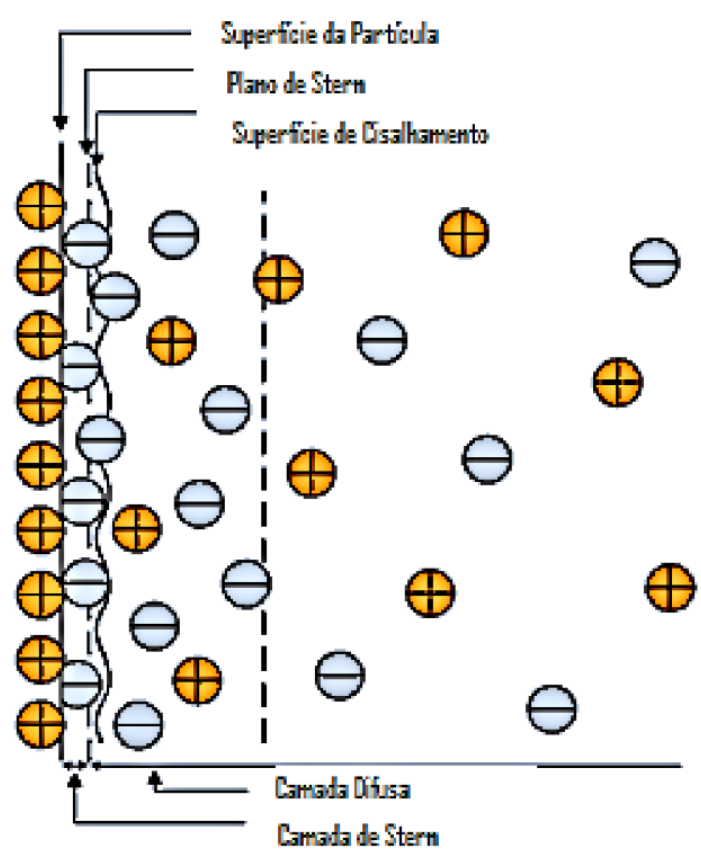

Figura 7. Esquema da camada de Stern ${ }^{[2]}$.

adequadamente a escolha do emulsionante. Por meio do cálculo do HLB é levado em conta o tamanho relativo dos grupos, que determina a curvatura preferida da interface, determinada pela fase dispersa, na escolha do emulsionante ${ }^{[1]}$.

\subsubsection{Teoria de Flory-Hugghins}

A Figura 8 ilustra a diminuição do grau de liberdade (ou movimento browniano), quando o tamanho do polímero é aumentado. A Figura 8a ilustra o efeito da adição de um polímero de cadeia curta (representado pelas esferas pretas), o qual confere maior grau de liberdade da menor estrutura organizada da emulsão (representada pelas esferas brancas). Já a Figura 8 b ilustra o efeito da adição de um polímero de cadeia longa (representado pelas esferas pretas interligadas), com a consequente diminuição do grau de liberdade das menores estruturas organizadas (representada pelas esferas brancas). Essa condição resulta em um sistema emulsionado 
com maior viscosidade. Esse é o fundamento da teoria de Flory-Hugghins: diminuição do movimento browniano, o que muitas vezes pode funcionar muito bem como estratégia para o aumento da estabilidade cinética ${ }^{[2]}$.

Este conceito pode ser aplicado em conjunto ao conceito de dupla camada elétrica (repulsão), se for necessário ampliar a interação para conseguir maior estabilidade. Nesse caso, o mais adequado é escolher um copolímero com parte hidrofílica aniônica para garantir a repulsão eletrostática ${ }^{[2,18,19]}$.

Pode-se considerar a entropia como a possibilidade de arranjos. A associação de copolímeros a uma formulação favorece o recobrimento da gotícula e contribui para a estabilização de todo o sistema, pela redução da mobilidade e, por consequência, da possibilidade de arranjos (entropia) ${ }^{[3,13]}$.

\subsubsection{Baixa fração volumétrica da fase dispersa}

Uma baixa fração volumétrica da fase dispersa garante um melhor empacotamento das gotículas. Para frações volumétricas muito elevadas, o amadurecimento de Ostwald (já definido previamente) é intrínseco ${ }^{[10,11]}$.

\subsubsection{Aumento da área superficial}

A orientação das moléculas interfere nas interações da interface. Nunca todas as moléculas estarão na mesma orientação por uma questão de entropia $(\Delta S)$, devido ao movimento browniano e aos choques que ocorrem (Figura 9). O mais adequado é que as gotículas sejam tão pequenas quanto possível e apresentem tamanhos uniformes para que não haja coalescência ${ }^{[3,4,13]}$.

Quando se usa a estratégia de aumentar a área superficial na interface, isso significa que ocorrerá o aumento do número de gotículas, portanto mais cisalhamento e mais energia são envolvidos no processo (o contrário é espontâneo). Nesse caso, os emulsionantes se concentram na superfície e menos energia é gasta para fazer o movimento da interface ${ }^{[25]}$. Quanto maior a cadeia apolar, maior a capacidade de reduzir a tensão superficial, portanto, menos energia é requerida ${ }^{[26,27]}$.

\section{Estudo da Influência de Diferentes Emulsionantes no Tamanho de Gotículas}

Este trabalho ilustra a influência de diferentes emulsionantes - aniônico (cetilfostato de potássio), catiônico (cloreto de distearildiamônio) e não-iônico (estearato de glicerina combinado com estearato de polietilenoglicol 100) - em concentrações diferentes (1, 3 e $5 \%$ em massa), na distribuição do tamanho de gotículas de uma formulação base de cosmético. A composição da formulação base é apresentada na Tabela 1.

As emulsões foram preparadas em escala laboratorial (600 g), com o auxílio de um misturador com hélice naval para a dispersão dos ingredientes apresentados na Tabela 1. $\mathrm{Na}$ fase de emulsificação fez-se a adição da fase oleosa sobre a fase aquosa, quando ambas as fases atingiram $80^{\circ} \mathrm{C}$. A fragrância foi adicionada sob agitação a $30^{\circ} \mathrm{C}$.

Os tamanhos das gotículas presentes nas diferentes fórmulas preparadas (Tabela 1) foram avaliados em um equipamento Malvern, modelo Mastersizer 2000, que tem como princípio de medida a difração de laser em amostras diluídas ${ }^{[28-30]}$. As amostras para estas análises foram cuidadosamente

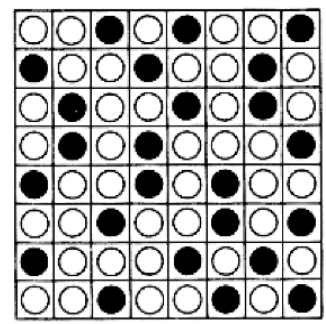

(a)

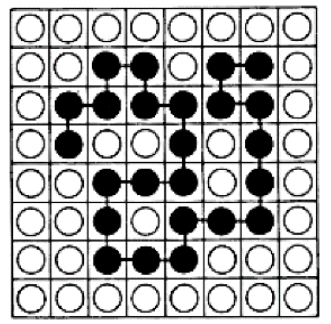

(b)

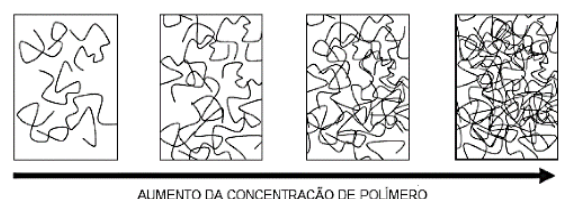

Figura 8. Esquema que ilustra a teoria de Flory-Hugghins ${ }^{[2]}$ (a) ilustra o efeito da adição de um polímero de cadeia curta (esferas pretas), o qual confere maior grau de liberdade da menor estrutura organizada da emulsão (esferas brancas). (b) ilustra o efeito da adição de um polímero de cadeia longa (esferas pretas interligadas), com a consequente diminuição do grau de liberdade das menores estruturas organizadas (esferas brancas).

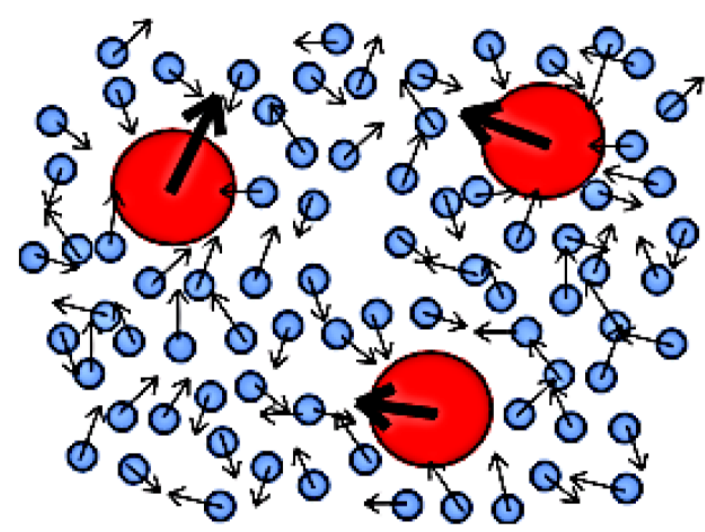

Figura 9. Esquema de movimento browniano ${ }^{[2]}$.

preparadas em pequenos frascos, onde a água (fase externa da emulsão) e a emulsão foram devidamente misturadas para resultar em um fluido diluído e visivelmente homogêneo. As análises foram realizadas em triplicata.

\subsection{Emulsionantes}

Os emulsionantes se dividem em três classes, quando o objetivo é aplicação em emulsões O/A: emulsionantes aniônicos, catiônicos e não-iônicos ${ }^{[1]}$.

\subsubsection{Emulsionantes aniônicos}

Os grupos polares aniônicos mais comuns são o carboxilato, sulfato e o fosfato. São os de maior volume de produção entre as categorias citadas e são utilizados na maior parte das formulações de sabões. A maioria dos emulsionantes aniônicos é produzida com cadeia carbônica entre 12-18 carbonos, pois nesta condição a solubilidade da porção oleosa é mais adequada ${ }^{[1]}$. 
Tabela 1. Composição da formulação base utilizada neste estudo que avalia a influência de emulsionantes aniônico, catiônico e não-iônico, em diferentes concentrações, na distribuição de tamanhos de gotículas.

\begin{tabular}{|c|c|c|c|c|c|c|c|c|c|c|c|}
\hline & \multirow{2}{*}{ Nome } & \multirow{2}{*}{ FUNÇÃO } & \multicolumn{3}{|c|}{ Aniônico } & \multicolumn{3}{|c|}{ Não-iônico } & \multicolumn{3}{|c|}{ Catiônico } \\
\hline & & & $\%$ & $\%$ & $\%$ & $\%$ & $\%$ & $\%$ & $\%$ & $\%$ & $\%$ \\
\hline \multirow{5}{*}{ 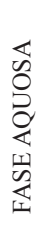 } & Água & Veículo & 81,40 & 79,40 & 77,40 & 81,40 & 79,40 & 77,40 & 81,40 & 79,40 & 77,40 \\
\hline & EDTA Dissódico & Agente quelante & 0,20 & 0,20 & 0,20 & 0,20 & 0,20 & 0,20 & 0,20 & 0,20 & 0,20 \\
\hline & Glicerina & Umectante & 5,00 & 5,00 & 5,00 & 5,00 & 5,00 & 5,00 & 5,00 & 5,00 & 5,00 \\
\hline & Hidroxietilcelulose & $\begin{array}{l}\text { Agente de } \\
\text { viscosidade }\end{array}$ & 0,30 & 0,30 & 0,30 & 0,30 & 0,30 & 0,30 & 0,30 & 0,30 & 0,30 \\
\hline & Trietanolamina & Ajuste de $\mathrm{pH}$ & 0,20 & 0,20 & 0,20 & 0,20 & 0,20 & 0,20 & 0,20 & 0,20 & 0,20 \\
\hline \multirow{7}{*}{ 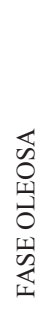 } & Álcool Benzílico & Conservante & 0,90 & 0,90 & 0,90 & 0,90 & 0,90 & 0,90 & 0,90 & 0,90 & 0,90 \\
\hline & Estearato de Glicerila & Emoliente & 1,00 & 1,00 & 1,00 & 1,00 & 1,00 & 1,00 & 1,00 & 1,00 & 1,00 \\
\hline & Óleo Mineral & Emoliente & 2,00 & 2,00 & 2,00 & 2,00 & 2,00 & 2,00 & 2,00 & 2,00 & 2,00 \\
\hline & $\begin{array}{l}\text { Lactato de Alquila } \\
\text { C12-C15 }\end{array}$ & Emoliente & 1,50 & 1,50 & 1,50 & 1,50 & 1,50 & 1,50 & 1,50 & 1,50 & 1,50 \\
\hline & $\begin{array}{c}\text { Triglicéride Cáprico/ } \\
\text { Caprílico }\end{array}$ & Emoliente & 1,00 & 1,00 & 1,00 & 1,00 & 1,00 & 1,00 & 1,00 & 1,00 & 1,00 \\
\hline & Dimeticone & Agente de sensorial & 0,50 & 0,50 & 0,50 & 0,50 & 0,50 & 0,50 & 0,50 & 0,50 & 0,50 \\
\hline & Álcool Estearílico & Emoliente & 1,20 & 1,20 & 1,20 & 1,20 & 1,20 & 1,20 & 1,20 & 1,20 & 1,20 \\
\hline \multirow{7}{*}{ 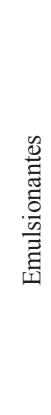 } & Álcool Cetílico & Emoliente & 2,80 & 2,80 & 2,80 & 2,80 & 2,80 & 2,80 & 2,80 & 2,80 & 2,80 \\
\hline & Fenoxietanol & Conservante & 0,70 & 0,70 & 0,70 & 0,70 & 0,70 & 0,70 & 0,70 & 0,70 & 0,70 \\
\hline & $\begin{array}{l}\text { Cetil Fosfato de } \\
\text { Potássio }\end{array}$ & Emulsionante & 1,00 & 3,00 & 5,00 & - & - & - & - & - & - \\
\hline & $\begin{array}{c}\text { Estearato de } \\
\text { glicerila combinado } \\
\text { com estearato de } \\
\text { polietilenoglicol } 100\end{array}$ & Emulsionante & - & - & - & 1,00 & 3,00 & 5,00 & - & - & - \\
\hline & $\begin{array}{c}\text { Cloreto de } \\
\text { diestearildomônio }\end{array}$ & Emulsionante & - & - & - & - & - & - & 1,00 & 3,00 & 5,00 \\
\hline & Fragrância & Perfume & 0,30 & 0,30 & 0,30 & 0,30 & 0,30 & 0,30 & 0,30 & 0,30 & 0,30 \\
\hline & & & 100 & 100 & 100 & 100 & 100 & 100 & 100 & 100 & 100 \\
\hline
\end{tabular}

Os contraíons mais utilizados são sódio, potássio, amônio e cálcio. Para os emulsionantes iônicos, o contraíon pode desempenhar importantes funções em suas propriedades físico-químicas, afetando, principalmente, a solubilidade em água $^{[2]}$. O sódio e o potássio promovem a rápida dissociação do emulsionante e uma elevada solubilidade em água, enquanto o cálcio auxilia na solubilidade do óleo. Por causa disso, os emulsionantes com contraíons de cálcio são normalmente utilizados na preparação de emulsões $\mathrm{O} / \mathrm{A}^{[1]}$.

$\mathrm{O}$ emulsionante escolhido neste estudo para representar esta classe foi o cetilfostato de potássio (Figura 10a), que possui o grupo polar aniônico fosfato e potássio como contraíon. Os motivos pelos quais este emulsionante foi escolhido se resumem à apresentação de dezesseis carbonos, que garantem boa solubilidade da porção oleosa da fórmula e à sua biocompatibilidade, já que possui grande similaridade às estruturas de fosfolipídios encontradas abundantemente na pele. O contraíon potássio garante também boa solubilidade com a porção aquosa das fórmulas.

\subsubsection{Emulsionantes catiônicos}

A maioria dos emulsionantes catiônicos apresenta pelo menos um átomo de nitrogênio como carga positiva. Tanto aminas como produtos baseados em quaternários de amônio são bastante comuns. As aminas somente funcionam como emulsionantes catiônicos quando protonadas, portanto só podem ser utilizadas como emulsionantes catiônicos em meios ácidos. Os compostos quaternários de amônio já não são tão sensíveis a variações de $\mathrm{pH}^{[1]}$.
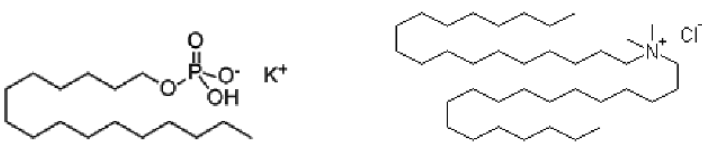

(a)

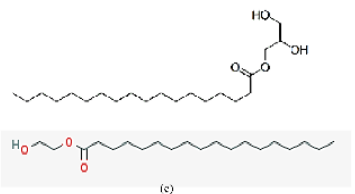

Figura 10. Estrutura química dos emulsionantes (a) aniônico: cetilfostato de potássio, (b) catiônico: cloreto de distearildiamônio e (c) não-iônico: estearato de glicerina combinado com estearato de polietilenoglicol 100 .

A carga positiva dos emulsionantes catiônicos permite que esses se adsorvam sobre os substratos carregados negativamente, sendo esses a maior parte dos substratos naturais, como pele e cabelo. Essa característica faz com que estes emulsionantes funcionem como agentes antiestáticos e amaciantes, já que aderem à superfície. Os emulsionantes fixos na superfície, que anteriormente estava carregada negativamente, mantêm sua parte lipofílica também aderida, gerando o efeito de lubrificação e a sensação de maciez ${ }^{[1]}$. Os substratos naturais são carregados negativamente porque as proteínas apresentam grande quantidade de hidroxilas. Essas hidroxilas normalmente apresentam certo grau de desprotonação em água (perda de $\mathrm{H}^{+}$), resultando em 
superfícies levemente negativas, quando em contato com a água ${ }^{[1]}$.

A presença de cargas negativas na pele por si só já é um fator de atração do emulsionante catiônico da emulsão na superfície, provocando adsorção. Associada a isso, a solubilidade em água dos emulsionantes catiônicos é, normalmente, menor que a dos aniônicos com o mesmo grupo apolar, o que também incentiva a adsorção à superfície da pele ${ }^{[1]}$.

Esta propriedade de adsorção altera a característica da superfície de hidrofílica para hidrofóbica, devido à adesão da porção hidrofóbica à pele, conferindo sensação de maciez. Altas concentrações de emulsionante catiônico podem provocar a formação de uma dupla camada de estabilização do emulsionante sobre a superfície, tornando-a novamente hidrofílica. Portanto, existem concentrações adequadas de uso desses emulsionantes para as diversas aplicações ${ }^{[1]}$.

A complexidade envolvida para a obtenção de quaternários de amônio - a molécula industrial mais simples utilizada como emulsionante catiônico - explica o fato de os preços serem normalmente mais elevados que os dos emulsionantes aniônicos e não-iônicos ${ }^{[1]}$.

$\mathrm{O}$ emulsionante catiônico escolhido para este estudo de caso foi o cloreto de distearildiamônio (Figura 10b), um quaternário de amônio com contraíon cloro. Vale mencionar que, os quaternários não são tão sensíveis à alteração de $\mathrm{pH}$, como as aminas. Nesse sentido, considerou-se a escolha de um quaternário mais adequada, levando-se em conta que o $\mathrm{pH}$ inicial das fórmulas avaliadas foi aproximadamente 5,5 (mesmo $\mathrm{pH}$ da pele), o que poderia promover algum tipo de alteração no estudo de estabilidade acelerada. Esta molécula possui duas cadeias de dezoito carbonos ligadas ao nitrogênio, que conferem boa solubilidade da porção oleosa da fórmula e experiência sensorial importante ao consumidor. Além dessas características, este emulsionante apresenta um desafio em termos de estabilidade cinética, pois este possui grupamentos significativamente grandes. Nesse sentido, a sua utilização permite aprendizados em termos de respostas reológicas e de processo. O contraíon cloro oferece rápida dissociação em água.

\subsubsection{Emulsionantes não-iônicos}

Durante as últimas quatro décadas, os emulsionantes não-iônicos vêm sendo cada vez mais utilizados, representando mais de $25 \%$ da produção mundial. Os emulsionantes não-iônicos não se dissociam em íons em solução aquosa e, por isso, são compatíveis com qualquer outro tipo de emulsionante, sendo muito utilizados em formulações complexas como coemulsionante ou emulsionante secundário ${ }^{[1]}$.

Existem diversos tipos de emulsionantes não-iônicos, mas o mercado é dominado pelos etoxilados, nos quais o grupo hidrofílico é formado por uma cadeia de moléculas de óxido de eteno polimerizada, fixada a uma parte apolar.

$\mathrm{O}$ emulsionante escolhido para representar esta classe neste trabalho foi o estearato de glicerina combinado com estearato de polietilenoglicol 100 . Um etoxilado que representa a categoria por estar consistentemente presente no mercado (Figura 10c).

\subsection{Distribuição de tamanhos de gotículas}

A Figura 11 é representativa das curvas de distribuição de tamanhos de gotículas, obtidas em triplicata para as formulações preparadas com os emulsionantes aniônico (cetilfostato de potássio), catiônico (cloreto de distearildiamônio) e não-iônico (estearato de glicerina combinado com estearato de polietilenoglicol 100), nas concentrações de 1,3 e $5 \%$ em massa da formulação base. As curvas apresentadas mostram diferentes perfis da distribuição dos tamanhos de gotículas por volume (\%), em função do emulsionante e da concentração utilizada. E, a análise dessas curvas mostra a melhor faixa de concentração para a aplicação dos três emulsionantes estudados na formulação base adotada.

Não foi possível criar a variante de concentração $1 \%$ do emulsionante catiônico, devido ao impedimento estérico das cadeias de carbono ligadas ao nitrogênio do carbono quaternário. Neste caso, não existiam moléculas de emulsionantes disponíveis o suficiente para organizar o sistema e formar glóbulos emulsionados.

A Tabela 2 apresenta os tamanhos de gotícula em micrometros $(\mu \mathrm{m})$, considerando $90 \%$ (D90) da população de gotículas para cada condição. Estes dados foram extraídos da Figura 11.

Os resultados evidenciam qual a melhor faixa de concentração para a base emulsionada, de acordo com o tipo do emulsionante. Para os emulsionantes catiônico e aniônico, a concentração mais adequada de emulsionante para a base utilizada é 3\% em massa. Isto é justificado ao observar o aumento do glóbulo emulsionado com o aumento da concentração do emulsionante para $5 \% \mathrm{em}$ massa. Isso caracteriza um sistema mais instável em termos cinéticos, com o aumento da concentração do emulsionante. Para o emulsionante não-iônico, a concentração mais adequada encontra-se em torno $3 \%$ e $5 \%$ em massa, já que o tamanho da menor unidade organizada do sistema está em contínuo decréscimo com o aumento da concentração. A partir da análise dos dados D90 (Tabela 2), observa-se que os três emulsionantes testados alteram a distribuição dos tamanhos das gotículas, sendo que o emulsionante aniônico na concentração de $3 \%$ em massa foi o que favoreceu a formação do sistema emulsionado com menor tamanho de gotícula. Neste caso, foi atingido o melhor empacotamento das menores estruturas organizadas no sistema emulsionado, ou seja, o sistema mais estável. A partir deste resultado, tem-se que o emulsionante aniônico selecionado - o cetilfostato de potássio - que possui o grupo polar aniônico fosfato e

Tabela 2. Distribuição de 90\% (D90) de tamanhos de gotículas para os três sistemas de emulsão estudados: aniônico, catiônico e não-iônico.

\begin{tabular}{lcc}
\hline \multicolumn{1}{c}{ Emulsionante } & $\begin{array}{c}\text { Concentração } \\
\mathbf{( \% )}\end{array}$ & D90 $(\boldsymbol{\mu m})$ \\
\hline Cetilfosfato de potássio & 1 & $31 \pm 1$ \\
(aniônico) & 3 & $19 \pm 0,5$ \\
& 5 & $116 \pm 1$ \\
Cloreto de diestearildiamônio & 3 & $54 \pm 1$ \\
(catiônico) & 5 & $76 \pm 0,6$ \\
Estearato de glicerina; Estearato & 1 & $68 \pm 2$ \\
de PEG 100 (não-iônico) & 3 & $59 \pm 1,5$ \\
& 5 & $44 \pm 0,6$ \\
\hline
\end{tabular}




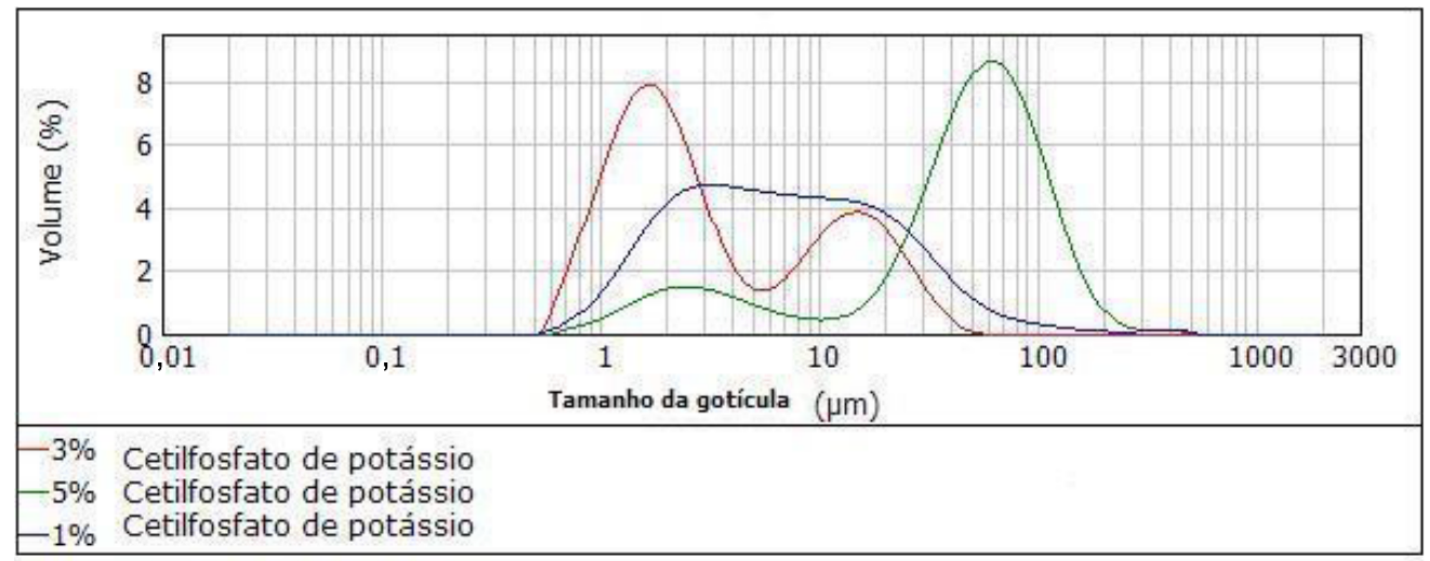

(a)

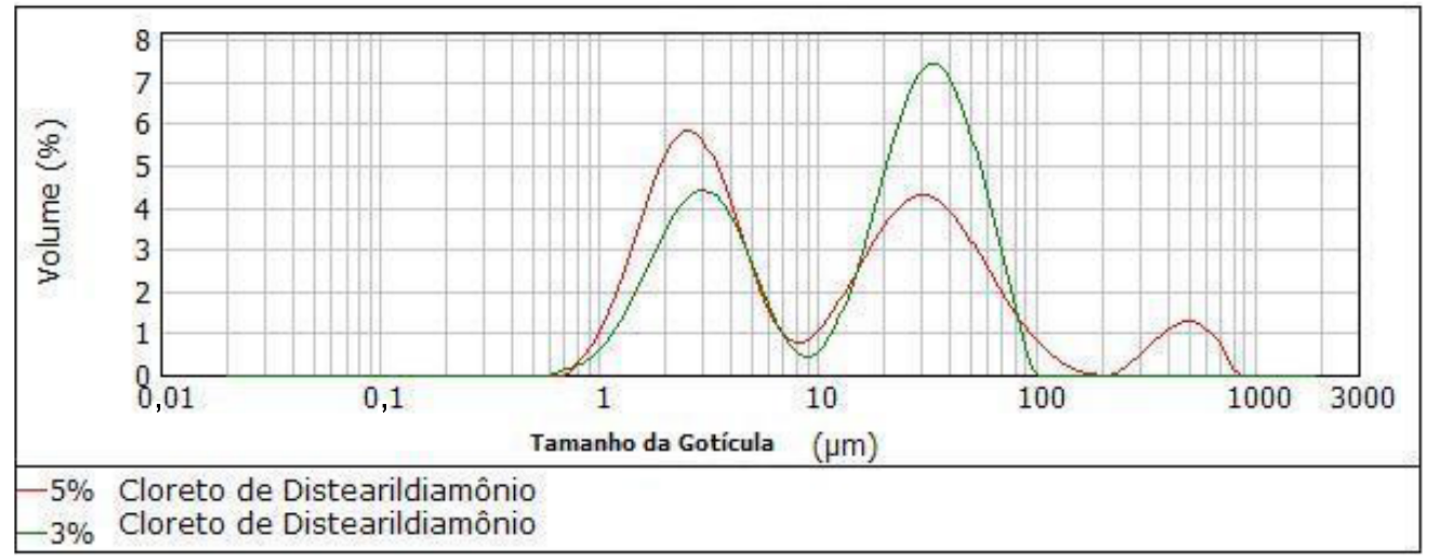

(b)

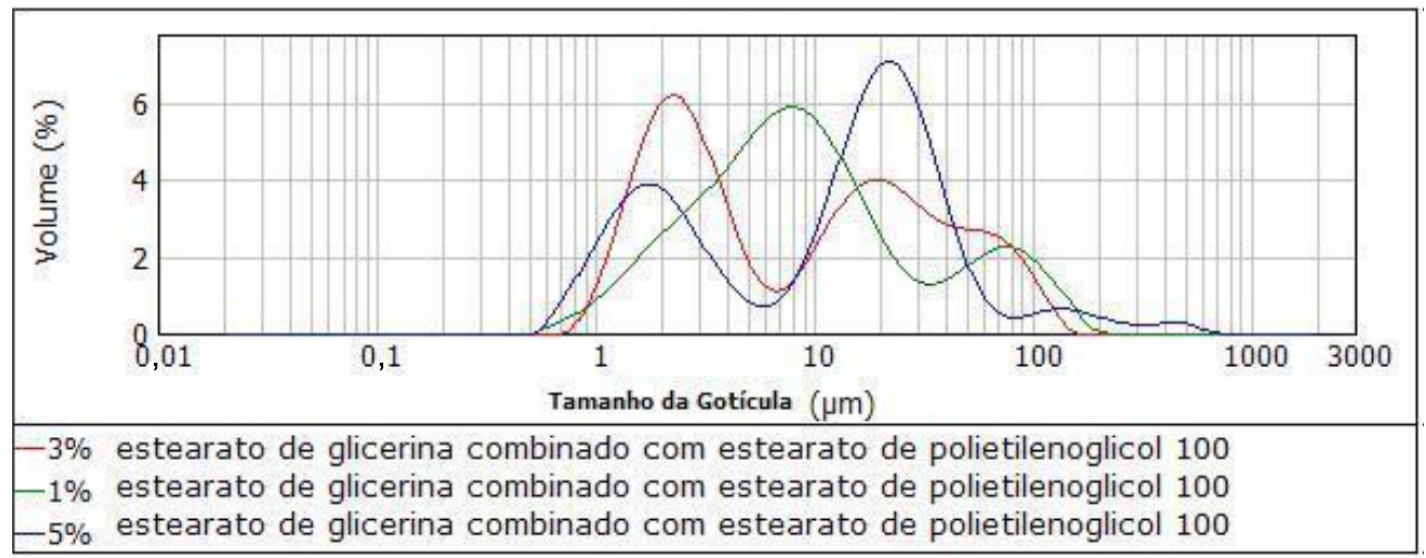

(c)

Figura 11. Gráficos representativos da distribuição de tamanho de gotículas para as emulsões (a) aniônica (cetilfostato de potássio), (b) catiônica (cloreto de distearildiamônio) e (c) não iônica (estearato de glicerina+estearato de polietilenoglicol 100).

o contraíon potássio, com dezesseis carbonos, favoreceu a melhor interação físico-química entre as porções oleosa e aquosa da fórmula base utilizada neste estudo.

A análise dos resultados mostra ainda que, com exceção do emulsionante não-iônico, não é observado o efeito da diminuição do tamanho dos glóbulos emulsionados, quando a concentração do emulsionante é aumentada. Esse comportamento é atribuído às interações químicas estabelecidas ao nível molecular, que não favorecem o decréscimo dos tamanhos das gotículas com o aumento do emulsionante. No caso dos emulsionantes cationico e aniônico, o aumento dos tamanhos das gotículas é atribuído à configuração química dos emulsionantes, que apresentam maior impedimento estérico, causado por dois grupamentos relativamente grandes, quais sejam, um átomo de nitrogênio e um grupo fosfato, respectivamente (Figuras 10a, b). 


\section{Conclusões}

Este artigo apresenta os principais conceitos relacionados ao tema emulsões, baseado em referências conceituadas da área, procurando contribuir principalmente com jovens pesquisadores ingressantes na área de emulsões. Este trabalho também evidencia o quanto é importante o conhecimento prévio das teorias de emulsões e das características químicas dos emulsionantes a serem utilizados na preparação de emulsões, visando obter sucesso na obtenção de sistemas cineticamente estáveis. Os resultados mostram que as características químicas dos emulsionantes e suas concentrações contribuem diferentemente na estabilidade do sistema.

Uma exploração prática é apresentada neste artigo, onde três emulsionantes dos tipos aniônico, catiônico e não-iônico, nas concentrações de 1, 3 e 5\% em massa, são utilizados em uma fórmula base. A comparação das formulações preparadas é baseada em medidas de tamanhos de gotículas das fórmulas com os três emulsionantes. Os resultados obtidos evidenciam que a natureza química do emulsionante é decisiva na estabilidade cinética de uma emulsão. De maneira não esperada, os resultados mostram o aumento do tamanho dos glóbulos emulsionados, quando as concentrações dos emulsionantes aniônico e catiônico são aumentadas. Esse comportamento observado mostra claramente a influência da estrutura química da molécula do emulsionante escolhido, onde a presença de grupamentos volumosos nas cadeias dos referidos emulsificantes promoveu o impedimento estérico, prejudicando o decréscimo dos tamanhos de partículas dos glóbulos emulsionados.

\section{Agradecimentos}

As autoras agradecem ao Professor Doutor Tharwat Tadros, consultor independente e professor da instituição internacional CfPA(The Center for Professional Advancement) pelas valiosas discussões e ensinamentos, ao Doutor Kamesh Yerramilli, diretor do setor de pesquisa e desenvolvimento da Johnson \& Johnson US-Skillman, por todo o apoio técnico prestado e ao CNPq (Processo: 303287/2013-6).

\section{Referências}

1. Daltin, D. (2012). Emulsionantes: química, propriedades e aplicações. São Paulo: Blucher.

2. Rosen, M. J. (2012). Surfactants and interfacial phenomena. London: Wiley.

3. Dettoff, R. T. (1993). Thermodynamics in materials science. New York: McGraw-Hill.

4. Tatterson, G. B. (2002). Process scale up and design. New York: McGraw-Hill.

5. McClements, D. J. (2010). Stability of food emulsions. Boston: University of Massachusetts.

6. Thomas, A. (2010). Colloidal phenomena. Boston: University of Massachusetts.

7. Rabinovich-Guilatt, L., Couvreur, P., Lambert, G., Goldstein, D., Benita, S., \& Dubernet, C. (2004). Extensive surface studies help to analyse zeta potential data: the case of cationic emulsions. Chemistry and Physics of Lipids, 131(1), 1-13. http://dx.doi org/10.1016/j.chemphyslip.2004.04.003. PMid:15210360.

8. Tadros, T. (2004). Application of rheology for assessment and prediction of the long-term physical stability of emulsions. Advances in Colloid and Interface Science, 108-109, 227-258. http://dx.doi.org/10.1016/j.cis.2003.10.025. PMid:15072944.
9. Tadros, T. (2004). Rheology of dispersions. London: Wiley.

10. Evans, D. F. (1994). The colloidal domain. New York: VCH.

11. Goodwin, J. W. (2010). Rheology for chemists. New York: Royal Society of Chemistry.

12. Castro, A. G. (2001). Reologia e suas aplicações industriais. São Paulo: Ciência e Técnica.

13. Chagas, A. P. (1999). Termodinamica química. São Paulo: Unicamp.

14. Taylor, P. (1998). Ostwald ripening in emulsions: estimation of solution thermodynamics of the disperse phase. Advances in Colloid and Interface Science, 75(2), 107-163. http://dx.doi. org/10.1016/S0001-8686(98)00035-9. PMid:14672850.

15. Taylor, P. (2003). Ostwald ripening in emulsions: estimation of solution thermodynamics of the disperse phase. Advances in Colloid and Interface Science, 106(1-3), 261-285. http:// dx.doi.org/10.1016/S0001-8686(03)00113-1. PMid:14672850.

16. Finsy, R. (2004). On the critical radius in Ostwald ripening. Langmuir, 20(7), 2975-2976. http://dx.doi.org/10.1021/ la035966d. PMid:15835181.

17. Tadros, T. (1996). Correlation of viscoelastic properties of stable and flocculated suspensions with their interparticle interactions. Advances in Colloid and Interface Science, 68(1-3), 97-200. http://dx.doi.org/10.1016/S0001-8686(96)00305-3.

18. Rakesh, K. G. (2000). Polymer and composite rheology. New York: Marcel Dekker.

19. Macosko, C. W. (1993). Rheology: principles, measurements and applications. London: Wiley.

20. Collyer, A. A. (1992). Rheology and processing of liquid crystal polymers. New York: Chapman \& Hall.

21. Damonte, S. P., Selem, C., Parente, M. E., Ares, G., \& Manzoni, V. (2011). Freshness evaluation of refreshing creams: Influence of two types of peppermint oil and emulsion formulation. Journal of the Society of Cosmetic Chemists, 62(6), 525534. Recuperado 12 de novembro de 2013, de http://journal. scconline.org/abstracts/cc2011/cc062n06/p00525-p00534. html

22. Silva, E. C., Paola, M. V. R. V., \& Matos, J. R. (2007). Análise térmica aplicada à cosmetologia. Revista Brasileira de Ciências Farmacêuticas, 43(3), 347-356. Recuperado em 08 de agosto de 2013, de http://www.scielo.br/pdf/rbcf/v43n3/a04v43n3. pdf

23. Lucas, E. F., Soares, B. G., \& Monteiro, E. (2001). Caracterização de polímeros: determinação de peso molecular e análise térmica. Rio de Janeiro: E-papers.

24. Tadros, T. (2005). Applied surfactants: principles and applications. London: Wiley.

25. Wiechers, J. W., \& Wortel, V. A. L. (2000). Making sense of sensory data. Cosmetic Toiletries, 115(3), 37-45.

26. Laba, D. (1993). Rheological properties of cosmetics and toiletries. New York: Marcel Dekker.

27. Barnes, H. A. (2000). Handbook of elementary rheology. Aberystwyth: University of Wales.

28. Allen, T. (1997). Particle size measurements. New York: Chapmann \& Hall.

29. Wedd, M. W. (2001). Procedure for predicting a minimum volume or mass of sample to provide a given size parameter precision. Particle \& Particle Systems Characterization, 18(3), 109-113. http://dx.doi.org/10.1002/1521-4117(200110)18:3<109::AIDPPSC109>3.0.CO;2-B.

30. Crosby, N. T. (1995). General principles of good sampling practice. New York: Royal Society of Chemistry.

Enviado: Jun. 02, 2014

Revisado: Dez. 04, 2014 Aceito: Jan. 12, 2015 